\title{
¿PODEMOS HABLAR DE UNA POSTURA DEL TRADUCTOR?
}

\author{
Juan ZAPATA \\ Universidad Charles de Gaulle, Lille 3
}

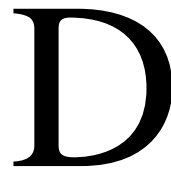
os hipótesis se encuentran en el origen de la cuestión que nos ocupa: la primera, puesta en evidencia por los trabajos recientes de Nathalie Heinich, remite a la necesidad de «examinar, como objeto de estudio en sí mismo, las representaciones que los actores se hacen del mundo, en lugar de considerarlas como una ilusión que debe ser desvelada mediante su confrontación con la realidad»(Heinich, 1998: 26). Es por esto que el análisis del estatuto del traductor no debe ocuparse únicamente de las condiciones materiales vividas por los actores (trayectorias, condiciones de trabajo, datos demográficos, instancias de difusión y de consagración, etc.), sino también de las representaciones que dichos actores construyen de sus prácticas para atribuirles una significación. La segunda, confirmada por los trabajos recientes sobre el estatuto del traductor y por el interés cada vez mayor que los medios y el mundo del libro le otorgan a esta figura, atañe al «aumento del prestigio de una función que carecía antes de visibilidad y era apenas nombrada» ${ }^{1}$. De ahí la necesidad de volver sobre la manera en la que el traductor (o más bien cierto tipo de traductores) construye una imagen de sí mismo para demarcar su posición en el campo editorial y mediático.

Esta primera aproximación al problema plantea de entrada una dificultad. Definida por Jérôme Meizoz «como la presentación que un escritor construye de sí mismo, tanto en la gestión del discurso

\footnotetext{
${ }^{1}$ Es la constatación que hace Jérôme Meizoz en una primera aproximación al problema. Correo del 26 de septiembre del 2013. Basta con echar un vistazo a los diferentes eventos culturales y publicaciones que buscan otorgar una mayor visibilidad mediática a la figura del traductor. En el 2012, el Consejo Europeo de Asociaciones de Traductores Literarios (CEATL) lanzó su programa anual Spot the translator cuyo objetivo es resaltar «la existencia y la importancia de los traductores literarios, sus desafíos y su función en el mundo del libro». La revista Translittérature, fundada y coeditada desde 1991 por la Asociación de traductores literarios de Francia (ATLF) y por la Asociación de la traducción literaria en Arles (ATLAS), cuyo objetivo es «reflexionar sobre el oficio del traductor y elaborar un discurso sobre esta actividad», consagra, en sus números semestrales, una sección entera a trazar retratos de traductores ejerciendo su trabajo. En 1999 y en el 2002, Jean Delisle publica dos obras colectivas, Portraits de traducteurs [Retratos de traductores] y Portraits de traductrices [Retratos de traductoras], cuyo objetivo es hacer penetrar al lector en la «intimidad» de diferentes traductores en diversas épocas. Festivales como VO-VF: Le monde en livres [VO-VF: El mundo en libros], cuyo objetivo es presentar anualmente la literatura mundial atribuyéndole únicamente la palabra a los traductores, son creados todos los años en diferentes países de Europa para resaltar la figura y la función del traductor. No olvidemos también las diferentes actividades que la Red Europea de Centros Internacionales de Traductores Literarios (RECIT) realiza, a través de sus diferentes colegios de traducción diseminados en varios países, para visibilizar al traductor.
} 
como en sus conductas públicas» (Meizoz, 2009) la noción de postura remite a un espacio ampliamente mediatizado en el que el escritor negocia una imagen identificable por sus pares y por el público ${ }^{2}$. Sin embargo, en el caso que nos ocupa, podemos afirmar con certitud que una gran parte de los traductores - profesionales u ocasionales, generalistas o especialistas- no acceden a una visibilidad mediática. Todos los traductores susceptibles de poseer una imagen pública no son profesionales (estos pueden también ser traductores ocasionales, como en el caso de los traductores universitarios en ciencias humanas o de ciertos traductores literarios para quienes la traducción no es más que un oficio secundario) y todos los traductores profesionales no son susceptibles de tener una imagen pública (traductor comercial, jurídico, judicial, medical, etc.). Es preciso pues preguntarse sobre las condiciones necesarias para que el traductor pueda revindicar una imagen reconocible tanto en sus tomas de posición discursivas como comportamentales.

Las diferentes categorías de traductores se definen en relación a los campos de traducción (estando estos ligados a su vez a su valor de cambio en la economía simbólica de los bienes culturales e intelectuales), al grado de especialización de sus funciones (ligadas por su parte a la estructura del mercado y a la cualificación adquirida a lo largo de una formación profesional) y a los cuadros jurídicos que las reglamentan. En lo que concierne a los campos de traducción y los grados de especialización, podemos establecer una primera distinción entre los traductores generalistas y los traductores especialistas. En el primer caso, el traductor, no habiendo capitalizado en un campo discursivo específico, se ve en la obligación de trabajar por encargo; se trata de un profesional polivalente al servicio de un patrón o empresario, razón por la cual se encuentra lejos de acceder a cualquier tipo de notoriedad. Este tipo de traductor no es pues susceptible de revindicar una imagen publica. Por el contrario, el traductor especialista, habiendo desarrollado unas competencias específicas en un campo particular, puede adquirir cierta notoriedad en el mercado de la traducción que le permitirá, gracias a ésta, comprometer su imagen pública en las exigencias de reconocimiento institucional.

Sin embargo, esta primera división no es suficiente para resolver el problema del acceso del traductor a una notoriedad que le permita desplegar una postura cualquiera. Es preciso pues introducir una nueva distinción en el seno mismo de los traductores especialistas. Aunque algunos textos (jurídicos, comerciales, farmacéuticos, etc.) exigen un grado de especialización considerable, éstos están desprovistos de la función autorial en el sentido que Michel Foucault le atribuyó a ese término (1969). Cuando el texto mismo no está oficialmente dotado de un autor, el traductor no puede tampoco reclamar la paternidad de su trabajo en términos de una propiedad intelectual. Éste podrá, eventualmente, colocar su nombre y exhibir un título que acredite su competencia (como en el caso del traductor jurado u oficial), esto es, una autoridad susceptible de cambiar en función de su posición institucional. Su nombre, sin embargo, no figurará en el texto en tanto productor de un

\footnotetext{
${ }^{2}$ «La postura -afirma Meizoz- desborda la identidad del hombre civil: esta reenvía a la cara pública o al "personaje” [...]
} de aquel que se presenta como escritor» (Meizoz, «Postures d'auteur et poétique»). 
discurso singular. Éste será el responsable del texto en cuanto a la fiabilidad de la traducción, certificada por una instancia oficial frente a la cual presta juramento, pero no un traductor susceptible de tener una imagen pública. Agreguemos que dichos textos, destinados a una circulación interna, aunque abierta al público, no son comercializables. En consecuencia, no exigen una paternidad traducible en derechos de autor, ni una imagen reconocible por el público. Llamaremos a este tipo de traductor, para retomar la expresión de Dominique Maingueneau a propósito de la diferentes dimensiones de la noción de autor, traductor garante . $^{3}$.

Podemos entonces concluir por el momento que la figura del traductor, susceptible de tener una imagen pública, sólo puede revelarse si el texto traducido reúne dos condiciones. Primero, debe ser un texto dotado de una función autor, en términos de una creación individual reconocible formal e históricamente, lo que le permite al traductor reclamar a su vez una autoridad (en el doble sentido del término) en el proceso de recreación del texto. El traductor tendrá pues sobre la traducción un derecho de paternidad comparable a aquel que tiene el autor sobre su obra. En segundo lugar, el texto traducido debe insertarse en un circuito de difusión y de comercialización, lo que le permitirá al traductor exhibir su nombre en la traducción y reclamar los derechos de propiedad intelectual. Esas dos condiciones son indisociables. Así, una traducción comercial (como en el caso de un manual de utilización) no es susceptible de atribuirle a su traductor una imagen, puesto que el texto mismo no activa ninguna función autor. Esta dimensión de la función del traductor la llamaremos desde ahora traductor autoritas para distinguirla de esa otra función en la cual el traductor cumple con su oficio sin por lo tanto exigir una visibilidad (traductor garante). Dicho de otra forma, y para retomar la formulación de Dominique Maingueneau, si toda traducción presupone la existencia de un traductor, sólo un número restringido de éstos accede al estatuto de traductor autoritas, esto es, de instancia dotada de una autoridad susceptible de conferirle una imagen pública.

Estas dos condiciones se reúnen particularmente en una esfera estética y mediática que haya alcanzado un alto grado de institucionalización (literatura, filosofía, ciencias humanas). Es allí que el traductor especialista puede reclamar para sí una autoridad y una visibilidad que lo diferencian de los traductores generalistas, funcionarios o técnicos. Un traductor que se especializa en unos de estos campos se convierte potencialmente en un traductor autoritas, susceptible de adquirir una imagen pública. Observemos, sin embargo, que todos los traductores incorporados a uno de estos campos no gozan del mismo grado de notoriedad, estando éste ligado a su vez a su posición institucional y a la manera en la que ocupa esta posición, esto es, a su postura. En efecto, un traductor profesional de literatura infantil o de literatura policiaca, esto es, un traductor que se posiciona en la esfera de gran producción, posicionamiento que le permitirá vivir eventualmente de su oficio, es un traductor autoritas en potencia; no obstante, para acceder a una visibilidad mediática, a una postura reconocible por el público y por sus pares, su proyecto de traducción (un autor, un grupo de autores,

\footnotetext{
${ }^{3}$ Retomamos aquí, parafraseándola, la distinción que Dominique Maingueneau (2009) hace a propósito de la diferentes dimensiones de la noción de autor. En efecto, un análisis similar al que Maingueneau hace en su estudio puede ser efectuado tomando como punto de partida la figura del traductor.
} 
un género en particular, un tipo de literatura) debe ir de la mano de un discurso de acompañamiento que construya la inteligibilidad de su proyecto y que transmita una cierta imagen de sí mismo. Sin dicho discurso, el traductor podrá gozar de una reputación en su medio, de una credibilidad que se traducirá a su vez en retribuciones económicas y simbólicas (número de encargos por año, puestos institucionales, etc.), sin que por ello acceda a una visibilidad mediática, a una voz y a una imagen singular que lo caractericen. Pero ya volveremos sobre este punto. Por ahora, es preciso señalar que las diferentes modalidades de puesta en escena de sí mismo se construyen en función de la posición institucional y del grado de notoriedad que ésta concede. Así, para dar un ejemplo, se puede distinguir en el interior del campo de la traducción diversas posiciones y maneras de ocuparlas ${ }^{4}$ : traductor ocasional (éste puede revindicar dos identidades: podemos entonces preguntarnos por el rol que juega la traducción en su proyecto socio-profesional); traductor de tiempo completo (éste puede ocupar una posición dominante o dominada, según su grado de reconocimiento institucional); traductor de renombre (dotado de un alto grado de reconocimiento, éste consagra las obras que traduce y, en la mayoría de los casos, traduce obras ya legítimas que lo consagran a su vez); traductor en ascenso (con un frágil reconocimiento institucional, sus decisiones de traducción, cuando no se trata de encargos que debe asumir, se orientan hacia autores cuyo prestigio puede consagrar al traductor); traductor de una literatura minoritaria (éste traduce las «diversas producción que la institución excluye del campo de legitimidad literaria») ${ }^{5}$; traductor fantasma (empleados al servicio de editoriales y de grandes traductores) ${ }^{6}$.

¿Pero cómo sale el traductor del anonimato y se hace visible? ¿Cómo construye esta credibilidad, esto es, esa imagen valorizante de sí mismo que él pone a disposición de sus pares y de su público? Evidentemente, el traductor que trabaja por encargo, y que no escolta su proyecto de traducción con un discurso de acompañamiento, difícilmente adquirirá una notoriedad que le permita desplegar una postura. Aunque obtenga una reputación en su medio, gracias al reconocimiento de sus competencias, como en el caso del traductor profesional de literatura infantil y policiaca del que hablábamos hace un momento, la ausencia de espacios de visibilidad, como los que otorga la crítica, los prefacios, las entrevistas, no le permite construir una imagen de sí mismo mediante la cual señale

\footnotetext{
${ }^{4}$ Sobre este punto, véase Nathalie Heinich (1984: 264-280). En su investigación realizada en 1983 para la A.T.L.F (Asociación de traductores literarios de Francia), Nathalie Heinich saca algunas conclusiones reveladoras. Al analizar las reivindicaciones de los dos grandes grupos que ella distingue entre los miembros de la A.T.L.F., los «traductores ocasionales» y los «traductores de tiempo completo», Heinich demuestra la existencia de dos lógicas discursivas opuestas que corresponden a lo que podríamos describir como dos posturas aparentemente antagónicas del traductor: por un lado, los traductores que se designan como profesionales (y que revindican un estatuto «jurídicamente controlado, provisto de una formación o de un aprendizaje sistemático y, en consecuencia, transmisible»); y, por el otro, los traductores que se designan como autores (y que viven la traducción como «don, como [una] vocación, y en el que el éxito, fuertemente individualizado, se mide menos en términos de ganancias materiales que en términos de reconocimiento simbólico, de "renombre"») (276).

${ }^{5}$ Retomamos aquí la definición de Jacques Dubois: «Llamaremos literaturas minoritarias a las diversas producciones que la institución excluye del campo de la legitimidad literaria o que aísla en las posiciones marginales en el interior de dicho campo» (Dubois, 2014: 104).

${ }^{6}$ A este análisis institucional de la posición del traductor, habrá que agregar también la posición que la lengua de partida y la lengua de llegada ocupan tanto en la cartografía lingüística mundial como en el mercado mundial de la traducción. A este respecto, véase Pascale Casanova (2002: 7-20).
} 
su existencia públicamente. Asimismo, desde un punto de vista metodológico, la ausencia de dichos espacios de expresión, desde los cuales el traductor autoritas negocia su imagen y legitima su proyecto de traducción, impiden una reconstrucción fidedigna de su postura. Por esta razón, un análisis de la postura de un traductor debe ante todo centrase en aquellos que, gracias a su alto grado de notoriedad, acompañan sus traducciones de discursos legitimantes que contribuyen a asegurar el éxito económico de su proyecto y a posicionar su figura en el interior de la institución (académica, literaria, mediática). Dichas estrategias editoriales y promocionales implican un conjunto de negociaciones, de actos de persuasión y de cálculos institucionales que constituyen la «escena de enunciación» (Maingueneau, 1993 y 2004) de su proyecto de traducción. Es en la construcción de esta «escena de enunciación», mediante la cual el traductor autoritas señala y refuerza su posición institucional, que éste invertirá en un discurso que le permite legitimar su proyecto de traducción y su propia figura. Si aceptamos lo anterior, aquello que va a diferenciar al traductor autoritas del traductor garante es su capacidad de posicionar, mediante un discurso de acompañamiento, su proyecto de traducción y su propia figura.

Así, para volver a nuestro punto de partida, nos queda pues por preguntarnos si la noción de postura, en tanto «manera personal de investir o de habitar una función, un estatuto» (Meizoz, 2014), puede ser adaptada al análisis de la figura del traductor. Ante todo, diremos que esta noción no puede aplicarse a la figura del traductor más que a condición de que ésta corresponda a lo que hemos llamado aquí traductor autoritas, esto es, a la imagen pública que el traductor co-construye en sus tomas de posición discursivas y comportamentales. Se trata en efecto de una puesta en escena de sí mismo que articula los actos de la persona civil, su función en tanto actor institucional y los discursos que la vehiculan ${ }^{7}$. Seguidamente, es preciso también «preguntarse por los tipos de materiales disponibles y por la manera en la que se colectan y se interpretan» ${ }^{8}$. De ahí la necesidad de establecer de antemano si la postura de un traductor es identificable tanto en los «hechos discursivos» como en las «conductas de vida». En lo que concierne a la primera dimensión, diremos que el traductor autoritas señala y negocia su posición institucional gracias al discurso de acompañamiento que éste construye para posicionar su proyecto de traducción. Es en sus prefacios, en sus retratos hagiográficos, en sus blogs, en sus entrevistas (donde el traductor explica su sistema de traducción, sus decisiones editoriales y su idea de lo que es un buen traductor) que éste revindica una autoridad y construye una imagen singular de sí mismo que lo distinguirá de la competencia. En lo que concierne a «la dimensión no discursiva (el conjunto de conductas no verbales de autorepresentación: vestido, gestos, aspecto, etc.)»(Meizoz, 2014), es evidente que ésta es menos visible que en la postura de autor, objeto de una fuerte mediatización. Menos carismática, y en

\footnotetext{
${ }^{7}$ Siguiendo la distinción de Dominique Maingueneau entre «la persona (ser civil); el escritor (la función-autor en el campo literario); el escriptor (la instancia enunciativa en el texto)», Jérôme Meizoz (2009) postula que «estudiar una postura, es abordar en conjunto (y cruzando estos elementos, con la prudencia que se requiere) las conductas del escritor, el ethos del escriptor y los actos de las persona».

${ }^{8}$ Es la constatación que Frédérique Giraud y Émilie Saunier hacen en su artículo titulado «La posture littéraire à l'épreuve de deux cas empiriques».
} 
consecuencia menos mediatizada, la figura del traductor participa de aquello que Lawrence Venuti ha descrito como la invisibilidad del traductor (Venuti, 1995), esto es, de una «ilusión de transparencia» discursiva (la traducción debe leerse como si se tratara del original, dicho de otro modo, sin que aparezca la figura del traductor-mediador) que relega a la sombra su figura institucional y su estatuto. Observemos, sin embargo, la existencia de diversos espacios en los que el traductor autoritas puede desplegar una postura comportamental, estando éstos ligados a la profesionalización y a la socialización progresiva del oficio: centros de formación, asociaciones y agencias de traductores, premios y residencias de traducción, eventos académicos y festivales. Se trata, ciertamente, de espacios de acumulación de un capital simbólico y de promoción mutua, pero también, y sobre todo, de verdaderos espacios en los que se construye un imaginario en torno de la profesión que alimentará a su vez las prácticas. Ocurre también que el traductor participe activamente de la promoción mediática de la obra traducida, ya sea acompañando al autor en sus apariciones públicas (firmas de libros, conferencias en el extranjero, lanzamientos, etc.), ya sea representando al autor (como en el caso de los autores fallecidos). Allí también, en tanto comentador destacado y promotor, el traductor autoritas puede desplegar una imagen de sí mismo.

Asimismo, a diferencia de la noción de ethos, que hace referencia a la imagen discursiva que construye un escriptor en un texto (Maingueneau, 2004), la noción de postura se refiere «a la imagen que el escritor construye a lo largo de una serie de textos firmados con su nombre». Dicho de otra forma, ésta «se elabora en el curso de un periodo y de manera acumulativa» (Meizoz, 2009). Así, como su noción vecina, de la cual ésta no es sino una prolongación, la postura del traductor no remite a un texto (la traducción de un libro, por ejemplo, o un prefacio aislado), sino que hace referencia a varios actos institucionales mediante los cuales el traductor se posiciona, lo que hemos llamado aquí el proyecto de traducción. De esta manera, la noción de postura, tal y como la define Meizoz, nos permite articular las tomas de posición discursivas del traductor (discursos de acompañamiento a sus traducciones) y su trayectoria profesional en un campo intelectual dado. Por último, aunque las instancias editoriales y comerciales no se ocupen siempre de la figura del traductor (los premios de traducción, por ejemplo, no son un argumento comercial para editores y libreros), la crítica periodística y académica, sin olvidar los jurados de los premios de traducción, concede, en ciertos casos, un lugar importante al traductor autoritas. Diremos entonces que, en la medida en que dichas instancias contribuyen a forjar una imagen del traductor, identificable y analizable en sus discursos, el análisis de la postura del traductor debe también tenerlos en cuenta por la simple razón de que el traductor autoritas se ve obligado a negociar permanentemente con éstas su imagen y su posición.

Quisimos interrogarnos acerca de las condiciones necesarias para hablar de una postura del traductor. No se trata, pues, de esbozar aquí una posturología, sino de establecer ciertos referentes para un análisis descriptivo cuyo objetivo es establecer las diferentes maneras de ser traductor, de construir y de legitimar su posición profesional.

\section{Referencias bibliográficas}


Casanova, P. (2002): «Consécration et accumulation de capital littéraire. La traduction comme échange inégale», Actes de la recherche en sciences sociales, 144, pp. 7-20.

DuBoIs, J. (1986): L'institution de la littérature. Bruselas, Labor.

(2014): La institución de la literatura. Trad. de Juan Zapata. Medellín, Editorial Universidad de Antioquía.

GIRAUD, F. y E. SAUNIER (2012): «La posture littéraire à l'épreuve de deux cas empiriques», COnTEXTES, en http://contextes.revues.org/4892 (última consulta, 17-11-2014).

HeINICH, N. (1998): Ce que l'art fait à la sociologie. París, Editions de Minuit.

- (1984): «Les traducteurs littéraires: l'art et la profession», Revue française de sociologie, 25-2, pp. 264-280.

Maingueneau, D. (1993): Le Contexte de l'œuvre littéraire. Enonciation et société. París, Dunod.

- (2004): Le discours littéraire. París, Armand Colin.

- (2009): «Auteur et image d'auteur en analyse du discours», Argumentation et Analyse du Discours, en http://aad.revues.org/660 (última consulta, 17-08-2013).

MeIzoz, J. (2009): «Ce qu'on fait dire au silence: posture, ethos, image d'auteur», Argumentation et Analyse du Discours, en http://aad.revues.org/667?lang=en.

—Postures d'auteur et poétique (Ajar, Rousseau, Céline, Houellebecq)», Voix-poetica. Lettres et sciences humaines, en http://www.vox-poetica.org/t/articles/meizoz.html (última consulta, 15-01-2014).

VENUTI, L. (1995): The translator's invisibility. Londres y Nueva York, Routledge. 